\title{
Optimization of Media and Cold Pretreatment for Anther Culture Using Japonica/Indica and Indica/Indica Hybrids and their Callus Induction Comparisons in Different Rice Crosses
}

\author{
Golam Faruq ${ }^{*}$, Fathonah Shamsuddin, August Jenifer, Siti Hajar Jusoh, \\ Arash Nezhadahmadi and Nurzulani Khalid \\ Institute of Biological Sciences, Faculty of Science, University of Malaya, Kuala Lumpur, \\ 50603, Malaysia; faruq@um.edu.my
}

\begin{abstract}
Rice (Oryza sativa) is pivotal to the lives of a large number of people around the world. Nowadays, anther culture is widely used in rice improvement as it can increase the selection efficiency. By optimizing the induction media and preservation time for cold pre-treatment, a significant improvement of embryogenic potential of the callus has been obtained in 3 different crosses of indica and japonica rice cultivars. It was observed that medium $2 \mathrm{~A}$ was the best among the others as it was capable to induce a great number of calli while the addition of silver nitrate to the N6 medium doubled up the production of embryogenic calli. Analysis of variance indicated that there was a significant interaction between medium and cold pre-treatment. Seven days of preservation time showed much better callus production in N6 medium compared to MS medium. Significant differences of the callus induction were observed among indica cultivars. Therefore, seven days cold pre-treatment in the combination of silver nitrate in N6 medium can be used in practicing anther culture technique in indica rice. Anther culture technique was also used in twelve rice genotypes that consisted of three different rice crosses namely indica aromatic $\times$ japonica aromatic, indica aromatic $\times$ indica aromatic, and indica non-aromatic $\times$ indica aromatic to produce and comparisons of callus induction. It was found that MRQ50×Rambir Basmati genotype grew faster than other genotypes. Meanwhile, MR219×Rato Basmati took longest time to grow up and MR219×Sadri produced more callus than other genotypes. In addition, the indica non-aromatic $\times$ indica aromatic cross had the highest frequency in callus formation. Finally, the genotypes that produced more callus could be used as potential breeding material.
\end{abstract}

Keywords: Media Optimization, Cold Pretreatment, Anther Culture, Callus Induction, Rice Crosses

\section{Introduction}

Rice (Oryza sativa L.) is the most important cereal crop in the world which is a staple food for more than one-third of the world's population. Because of its political, economic, and social significance, rice remains to be the most important crop grown in Southeast Asia ${ }^{1}$. In these areas, the population is rapidly increasing ${ }^{2}$, however, the growth of rice production is not as compatible as requested ${ }^{3}$. Tissue culture techniques are suitable biotechnological approach to increase the productivity of crops. It involves the induction of embryo formation from immature pollen and subsequent regeneration of embryo into plantlets ${ }^{4}$. This technique has long been utilized as an important tool for producing haploids ${ }^{5}$. It has numerous advantages such as the high selection efficiency, gametoclonal variants,

*Author for correspondence 
developed genetic variability, shortened breeding time, assessing recessive traits in intact plants ${ }^{6}$, and being very effective for double haploid production ${ }^{7}$. Anther culture is discovered by Guha and Maheshwari ${ }^{8}$, has been used in haploid production by Niizeki and Oono ${ }^{9}$. This technique has been used successfully to produce homozygous breeding lines in rice, especially in japonica rice $^{10}$. However, the potential of anther culture in indica rice is yet to be fully exploited due to various constraints that include a recalcitrant genetic background in the indica varieties. This statement has also been confirmed by Morinson and Evans ${ }^{11}$ in which the efficiency of indica rice is much lower compared to japonica. Japonica cultivars are much easier to be cultured than indica ${ }^{12,13}$. Callus induction and subsequent regeneration are the following steps of anther culture procedure. Many factors can affect the callus induction such as genotypes of the explants, composition of medium, culture conditions and methods, growth condition of the donor plants, developmental stage of microspores and pretreatment ${ }^{14}$. Among them, the medium composition ${ }^{15}$ and cold pretreatment ${ }^{16}$ are regarded to be the most influencing factors in rice in vitro culture. Normally, anthers start callusing after about four ${ }^{7,17}$ or three weeks ${ }^{18}$ of incubation. $\mathrm{Li}^{19}$ demonstrated that the earliest calli formed at 10-15 days after culture. Normally, japonica varieties and indica $\times$ japonica hybrids need three weeks to initiate callus formation. However, the anther response of japonica and japonica $\times$ indica hybrids was quicker in N6 medium and formed visible callus after $3-4$ weeks compared to $5-6$ weeks in the B5 and Miller media ${ }^{18}$. Abe and Futsuhara ${ }^{13}$ reported that genetic variability among japonica, indica, and javanica varieties was responsible for their variation in callusing ability. Optimizing the growth media can have influence on the yield of calli which regenerated green plantlets. This has also been confirmed by several scientists ${ }^{20,21}$ that optimization on the plant growth regulators play a great role in tissue culture. According to Roy and Mandal ${ }^{22}$, the phytohormones, organic adjuvants and carbon sources also can influence the callus formation. Chen et al. ${ }^{15}$ explained that cold pre-treatment is used as an inductive treatment in most of the studies. The application of cold pre-treatment may vary with the species or even varieties. Some researchers $7,17,18$ treated the panicles in cold environment within 7 days, others ${ }^{22,23,24}$ conducted it within 8 days, and Ong et al. ${ }^{25}$ used 10 days for cold pre- treatment. N6 medium is widely used as a plant growth medium that was reported by Chu et al. ${ }^{26}$. Just like MS, N6 consists of macronutrients, micronutrients and vitamins. It has been extensively studied that N6 medium showed excellent response to callus induction compared to MS medium ${ }^{17,18}$. According to Roy and Mandal $^{22}$, N6 supplemented with organic adjuvants like yeast extract, casein hydrolysate and coconut water showed enhanced androgenic callus induction in indica rice to a considerable extent. The indica varieties had high callus induction frequencies in B5 medium rather than in N6 and Miller media ${ }^{18}$. General trend of variation in anther culture among rice genotypes reported that callus formation among japonica rice was more than indica $\times$ japonica. However, this hybrid formed more callus compared to indica $\times$ indica, whereas indica $\times$ indica had more callus formation than in indica rice ${ }^{27}$. The maximum callus induction of indica aromatic varieties were recorded when N6 was supplemented with $3 \%$ and $6 \%$ of maltose ${ }^{22}$. For the effect of organic adjuvants, high callus induction (\%) was observed at low concentration $(200 \mathrm{mg} / \mathrm{l})$ of yeast extract in all anther culture indica aromatic varieties ${ }^{22}$. When the indica non-aromatic was crossed with indica aromatic rice, more non-aromatic plant was produced as the aroma is controlled by a single recessive gen $\mathrm{e}^{28}$. Japonica cultivar as a non-aromatic rice and neutral in flavor is greatly studied by scientists ${ }^{29}$. A study conducted by $\mathrm{Sah}^{7}$ reported that callus forming ability from rice anthers was high in the medium supplied with 2,4-D. NAA has also been studied to increase the production of the green plant compared to 2, 4-D. This researcher, therefore, concluded that great attention must be paid to the frequency of plant regeneration rather than high rate of callus induction. It has also been studied that the addition of $\mathrm{AgNO}_{3}$ to the medium improved callus induction and plant regeneration. The higher percentage of callus induction of indica aromatic rice was observed on $\mathrm{N} 6$ with $3 \%$ maltose 22 . In indica $\times$ japonica hybrid, the mean of callusing frequency in LS medium was lower than MS or $\mathrm{N}^{14}$. This frequency of callus had the same results as Chung ${ }^{30}$ by using indica $\times$ japonica. Zaidi et al. ${ }^{21}$ conducted study on optimizing the concentration of carbohydrate sources, agar, amino-acid supplements and hormones. It was found that maltose was the most effective carbohydrate as it gave the highest frequencies of callus induction, embryogenic calli, and green plant regeneration. A study performed by Jain et al. ${ }^{31}$ also confirmed the effectiveness of maltose for indica cultivars. Sucrose on the other hand, was shown to decrease the production of calli and plant regeneration as it helped 
excise tissues to make more ethylene under in vitro conditions and this was resulted in the callus browning ${ }^{32}$. By splitting the sucrose to other sugars; fructose and glucose, this may result in disruption on the plasmadesmatal connections between pre embryonic cells ${ }^{33}$. Thus, this mechanism allows the cells to be physiologically isolated and differentiated ${ }^{31}$. In recent years, silver ion in the form of nitrate has been extensively studied as it is related to the inhibition ethylene biosynthesis in anther culture program. According to Beyer ${ }^{34}$ and Zhao et al. ${ }^{35}$, silver nitrate is known to interfere with ethylene action and forming complexes which inhibits ethylene responses. In the present investigations, it was tried to optimize media and cold pretreatment which are very crucial for callus induction and also to compare the successful induction rates in different Japonica/Indica, Indica/Indica rice crosses.

\section{Materials and Methods}

Genotype E7 (IR 77734-93-2-3-2; Japonica) and E11 (IR 78554-145-1-3-2; Japonica) and Garib and E13 (IR 775122-1-2-2; Indica) were collected from International Rice Research Institute (IRRI) and Malaysian popular cultivar MR219 and MRQ 50 were obtained from Malaysian Agricultural Research Development Institute (MARDI). Several crosses were made among Rambir Basmati, Rato Basmati, Sadri, Gharib, MR219 and MRQ50 at Institute of Biological Sciences, University of Malaya, Malaysia during November 2011 under a crossing plan of indica aromatic $\times$ indica non-aromatic, indica aromatic $\times$ indica aromatic, and indica aromatic $\times$ japonica non-aromatic. Progenies were raised from $\mathrm{F}_{1}$ seeds and used for cold pretreatment. After that anthers were obtained and used for media optimization to compare callus induction in different crosses.

\subsection{Growth Condition and Media Preparation}

The experiments were conducted at experimental field and plant biotechnology laboratory of Institute of Biological Science, Faculty of Science, University of Malaya. Normal media which is also called Media 1 consisted of 2 types of basic media; $\mathrm{MS}^{36}$ and N6 ${ }^{26} 1000 \mathrm{ml}$ of MS medium was made and the required volume of all the ingredients (macronutrient, micronutrient and vita$\mathrm{min}$ ) were calculated and obtained into a $1000 \mathrm{ml}$ Schott bottle. The medium was then supplemented with $0.25 \mathrm{ml}$ of 2,4-D, $5 \mathrm{ml}$ of FeEDTA, $1 \mathrm{ml}$ of NAA, 10g of sucrose, and $0.05 \mathrm{~g}$ of myo-inositol. The $\mathrm{pH}$ was then adjusted to 5.7 and the solution was topped up with distilled water until $1000 \mathrm{ml}$. Finally, $1 \mathrm{~g}$ of gelrite was added and stirred until fully dissolved. The medium was autoclaved for $121^{\circ} \mathrm{C}$ and distributed into each sterile petri dish in the laminar flow, allowed to solidify, and stored for use. The same ingredients were required for $1000 \mathrm{ml} \mathrm{N6}$ medium while FeEDTA was not included.

\subsection{Media Optimization and Sample Preparation}

Medium 1 consisted of 2 types of basic media; MS and N6. Three different optimized media designated as medium 2 , 3 , and 4 were prepared by supplying the following ingredients: Medium 2: N6 + 0.5mg/l 2,4-D + 2mg/l NAA + $10 \mathrm{mg} / \mathrm{l} \mathrm{AgNO}_{3}$ and $\mathrm{MS}+0.5 \mathrm{mg} / \mathrm{l} 2,4-\mathrm{D}+2 \mathrm{mg} / \mathrm{l} \mathrm{NAA}+$ 10mg/l $\mathrm{AgNO}_{3} ;$ Medium 3: N6 + MS + 0.5mg/l 2,4-D + $2 \mathrm{mp} / \mathrm{l} \mathrm{NAA}+10 \mathrm{mg} / \mathrm{l} \mathrm{AgNO}_{3}$; Medium 4: medium 3 without $\mathrm{AgNO}_{3}$. Just like normal media, $\mathrm{pH}$ was checked; $1 \mathrm{~g}$ gelrite was added and autoclaved which was ready to be distributed to each petri dish. The collection of panicles of the $\mathrm{F}_{1}$ plants was done within the reproductive phase within uni-nucleate to early bi-nucleate stage following Silva and Ratnayake ${ }^{17}$ and the auricle distance of the flag leaf to that of the next leaf sized 5-9 $\mathrm{cm}$ following Tran and Vuong ${ }^{24}$.

\subsection{Pre-cold Treatment of Panicles}

In pre-cold treatment, each material was prepared by keeping the boot intact with its penultimate leaf sheath and node, while flag and extra basal node were trimmed described by Sah? ${ }^{7}$. Panicles were washed with tap water, surface-sterilized with $70 \%$ ethanol for 5 minutes, wrapped in moist tissue papers at the base of cut surface of the panicles, and kept in the polyethylene bags at $5^{\circ} \mathrm{C}$ for 7 days emphasized by Herath et al. ${ }^{18}$. At this stage, the samples were treated at different preservation time; 5, 7, $8,9,10,14,21$ days to scrutinize different callus induction responses from each genotype.

\subsection{Surface Sterilization}

Surface sterilization was done as mentioned by Silva and Ratnayake ${ }^{17}$. Callus induction was started by sterilizing the plant surfaces in which the upper and bottom parts 
of the panicles were trimmed, only the middle parts were used. They were rinsed with $70 \%$ ethanol for 20 seconds. The spikelets were then removed from the upper, middle, and lower portion of tiller and soaked with $30 \%$ Clorox for 20 minutes. The aim was to represent the maturity gradient of the florets. Finally, the collected spikelets were rinsed with distilled water which was ready to be cultured. Anther culture was carried out inside the laminar flow near the Bunsen burner flame. Anthers were dissected out by snipped at the base while holding from the tip in order to detach them from the filaments. For normal media, an average of 6 anthers was dropped onto each media which made the total of 20 anthers each petri dish. For each optimized media, an average of 6 anthers was randomly plated onto each part with two replications. After inoculation, cultures were finally sealed and kept in dark growth room at $25^{\circ} \mathrm{C}$ for callus induction. Anther response was evaluated after approximately four weeks, and every week thereafter.

\subsection{Callus Induction}

The formation of callus was observed until the $6^{\text {th }}$ week. The callus induction frequency (percentage of anthers forming calli) was recorded on the 6th week. This formula was used to calculate the callus induction frequency (CIF):

$$
\mathrm{CIF}(\%)=\frac{\text { Number of anther producing calli }}{\text { Number of anther cultured }} \times 100
$$

\subsection{Data Analysis}

The SAS 9.2 and XLSTAT version 2011 software were used for statistical analysis.

\section{Results}

Responses of genotypes to culture media for callus induction from rice anthers were investigated. Anthers from genotypes were cultured in 4 different media namely medium 1A, 1B, 2A, 2B, 3 and 4 , and 2 replications were carried out. Callusing anthers were observed within 4-6 weeks and potential callus induction was highly per-

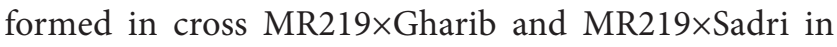
comparison with others. Results stated that the effect of media on callus induction in rice genotypes was highly significant. Table 1 illustrates the responses of anthers from MR219 $\times$ Gharib to the frequency of callus induction. The highest callus frequency was observed in medium
2A (66.7\%) which was N6 medium supplemented with 2,4-D and $\mathrm{AgNO}_{3}$, followed by medium 4 (56\%) which was a combination of N6 and MS medium supplemented with 2,4-D, medium 1A (33.3\%), medium 3 (9.1\%), medium 2B (3\%) and medium 1B (0\%). Table 2 shows the response of anthers from MR219×Sadri. The production of callus, however, was not consistent with its production in the first genotype (MR219×Gharib). The highest callus frequency was recorded in medium $1 \mathrm{~A}, 2 \mathrm{~A}, 4,3,1 \mathrm{~B}$, $2 \mathrm{~B}$ respectively. Information on the frequency of callus induction in optimization media from MR219×Gharib and MR219×Sadri crosses is demonstrated in Table 1. Based on this table, all frequency of callus induction showed in both crosses, referring to medium 1 and 2, callus formation from N6 media was highly superior compared to MS media that showed less frequency. In other words, the production of callus in MS medium was slower and lesser. The highest frequency of callus was influenced by the addition of $\mathrm{AgNO}_{3}$ which was observed in the medium 2A of MR219×Gharib cross. Supposedly, this medium (2A) should also be observed as the highest frequency among other media. However, the result from genotype MR219×Sadri was inconsistent. It showed that medium 1A had the best result for callus induction. It

Table 1. Response of anthers from MR219×Gharib cross to the frequency of callus induction (\%)

\begin{tabular}{lccc}
\hline Media & $\begin{array}{c}\text { No. of anthers } \\
\text { cultured }\end{array}$ & $\begin{array}{c}\text { No. of callus } \\
\text { formed }\end{array}$ & $\begin{array}{c}\text { Frequency of } \\
\text { callus (\%) }\end{array}$ \\
\hline 1A & 36 & 12 & 33.3 \\
1B & 36 & 0 & 0 \\
2A & 36 & 24 & 66.7 \\
2B & 33 & 1 & 3 \\
3 & 33 & 3 & 9.1 \\
4 & 30 & 17 & 56 \\
\hline
\end{tabular}

Table 2. Response of anthers from MR219×Sadri cross to the frequency of callus induction (\%)

\begin{tabular}{lccc}
\hline Media & $\begin{array}{c}\text { No. of anthers } \\
\text { cultured }\end{array}$ & $\begin{array}{c}\text { No. of callus } \\
\text { formed }\end{array}$ & $\begin{array}{c}\text { Frequency of } \\
\text { callus (\%) }\end{array}$ \\
\hline 1A & 33 & 13 & 39.3 \\
1B & 32 & 2 & 6.2 \\
2A & 36 & 9 & 25 \\
2B & 36 & 1 & 2.7 \\
3 & 34 & 5 & 14.7 \\
4 & 30 & 6 & 20 \\
\hline
\end{tabular}


was also revealed that the addition of $\mathrm{AgNO}_{3}$ in media N6 and MS combination was very poor (medium 3), this suggested that the effect of silver nitrate was suppressed when N6 and MS were combined together. According to Table 3, MR 219×Gharib produced more number of callus than MR $219 \times$ Sadri in which there was a significant difference between MR 219×Gharib and MR 219×Sadri to the number of callus formed. However, MR219 $\times$ Rato Basmati did not form any callus. Another approach to increase the efficiency callus induction is to optimize the preservation time. MR219 $\times$ Gharib genotype was treated with different preservation times; fresh, 5, 7, 8, 9, 10, 14 and 21 days. These samples were cultured in normal N6 and MS media in 2 replications and responses of samples to culture media was investigated and callus development was observed within 4 and 6 weeks after inoculation of anthers. Significant interactions between hybrids and cold pre-treatment were observed. Table 4 shows the responses of callusing anthers to the MS media as the highest frequency of callusing anthers was recorded in

Table 3. Mean comparisons of cultured anther in three different rice crosses through Duncan Multiple Range Test (DMRT) in media optimization

\begin{tabular}{|c|c|c|}
\hline Cross & $\begin{array}{c}\text { Number of } \\
\text { cultured anther }\end{array}$ & $\begin{array}{l}\text { Number of } \\
\text { formed callus }\end{array}$ \\
\hline MR 219×Gharib & 204 & $57 \mathrm{~A}$ \\
\hline MR 219×Sadri & 201 & $36 \mathrm{~B}$ \\
\hline MR $219 \times$ Rato Basmati & - & - \\
\hline
\end{tabular}

Mean followed by the different latter in a column are significantly different from each other at $0.01 \%$ probability level

Table 4. Responses of anthers from MR219×Gharib to the frequency of callus induction (\%) in MS medium

\begin{tabular}{lccc}
\hline Time & $\begin{array}{c}\text { No. of anthers } \\
\text { cultured }\end{array}$ & $\begin{array}{c}\text { No. of callus } \\
\text { formed }\end{array}$ & $\begin{array}{c}\text { Frequency } \\
\text { of callus (\%) }\end{array}$ \\
\hline Fresh (0 days) & 49 & 3 & $6.1 \mathrm{~b}$ \\
5 days & 72 & 4 & $5.5 \mathrm{~b}$ \\
7 days & 67 & 7 & $10.4 \mathrm{a}$ \\
8 days & 52 & 5 & $9.6 \mathrm{a}$ \\
9 days & 121 & 0 & - \\
10 days & 64 & 0 & - \\
14 days & 56 & 1 & $1.8 \mathrm{~d}$ \\
21 days & 67 & 2 & \\
\hline
\end{tabular}

Mean followed by the different letter in a column are significantly different from each other at $0.05 \%$ probability level in Duncan Multiple Range Test (DMRT) sample which was preserved for 7 days (10.4\%). The formed callus was very small and not clear, however, many of callusing anthers were developed. The sample that was preserved for 8 days (9.6\%) also showed a good callus production followed by fresh condition (6.1\%), 5 days $(5.5 \%), 21$ days (3\%) and 14 days (1.8\%) whereby these anthers just started rooting and not showed visible callus, while 9 and 10 days of preservation time showed no callusing anthers at all. Table 5 illustrates the responses of samples to the frequency of callus induction in N6 medium. Likewise in MS medium, the highest frequency of callus was showed in sample with 7 days (36.8\%) followed by 8 days (23.4\%), 5 days (12.7\%), 10 days (12\%), fresh (9.5\%) and 21 days (3.1\%) preservation time. There was no callus development observed in 9 and 14 days of treatment. It implied that the application of cold pre-treatment for this duration of days was not sufficient. Twelve genotypes of rice that consisted of three different rice crosses such as indica aromatic $\times$ japonica aromatic, indica aromatic $\times$ indica aromatic, and indica non-aromatic $\times$ indica aromatic were subjected to produce callus. The callus induction frequency among 4 genotypes in indica aromatic $\times$ indica aromatic rice is showed in Figure 1. The results indicated that MRQ50/ Gharib showed the highest percentage of callus formation (19.91\%). MRQ50/Rambir Basmati and MRQ50/ E13 had the same value of callus induction frequency, $2.78 \%$. This was the lowest callus induction frequency in indica aromatic $\times$ indica aromatic rice crosses. Gharib/ MR219 had the highest value of callus induction frequency (16.67\%) which was more efficient in producing

Table 5. Responses of anthers from MR219×Gharib to the frequency of callus induction (\%) in N6 medium

\begin{tabular}{lccc}
\hline Time & $\begin{array}{c}\text { No. of anthers } \\
\text { cultured }\end{array}$ & $\begin{array}{c}\text { No. of callus } \\
\text { formed }\end{array}$ & $\begin{array}{c}\text { Frequency } \\
\text { of callus }(\%)\end{array}$ \\
\hline Fresh (0 days) & 63 & 6 & $9.5 \mathrm{~cd}$ \\
5 days & 63 & 8 & $12.7 \mathrm{c}$ \\
7 days & 76 & 28 & $36.8 \mathrm{a}$ \\
8 days & 64 & 15 & $23.4 \mathrm{~b}$ \\
9 days & 48 & 0 & - \\
10 days & 58 & 7 & $12 \mathrm{c}$ \\
14 days & 30 & 0 & - \\
21 days & 64 & 2 & $3.1 \mathrm{~d}$ \\
\hline
\end{tabular}

Mean followed by the different letter in a column are significantly different from each other at $0.05 \%$ probability level in Duncan Multiple Range Test (DMRT) 
callus (Figure 1). However, the percentage of callus formation was $4.17 \%$ and $4.07 \%$ in MR219/E13 and MR219/ E11 respectively which were slightly similar to each other. Finally, MR219/E7 showed the lowest rate (1\%). From Figure 1 genotypes of indica non-aromatic $\times$ indica aromatic rice crosses showed the significant value of callus induction frequency. MRQ 50/Gharib showed the highest rate in comparison with others (19.91\%) followed by MR219/Sadri (19.64\%), Gharib/MR 219 (16.67) and MR219/Gharib (10.83\%) respectively and MR219/E17 performed lowest induction rate (1\%) (Figure 1). Indica non-aromatic $\times$ indica aromatic rice crosses showed the highest value of callus induction frequency (52\%) compared to indica $\times$ japonica $(22 \%)$ and indica aromatic $\times$ indica aromatic (26\%) rice crosses (Figure 2). The calli from these crosses have been successfully formed on N6 media supplemented with $0.5 \mathrm{mg} / 1$ 2,4-Dichlorophenoxy acetic acid and 2mg/l NAA (napthaleneacetic acid), preserved in 8 days. According to table 6, indica nonaromatic $\times$ indica aromatic rice crosses showed the highest number of formed callus which was significant with other crosses.

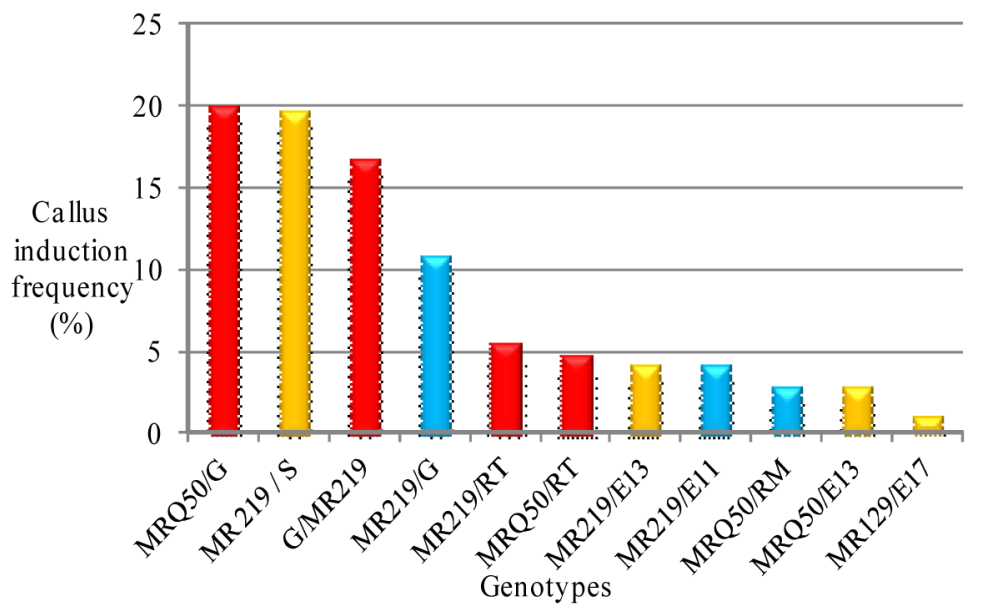

Figure 1. The callus induction frequency among 11 genotypes in 3 different rice crosses.
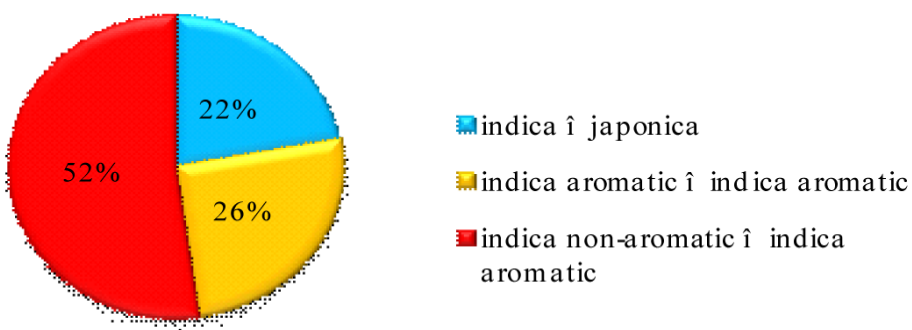

Figure 2. The callus induction frequency between three different rice crosses. 
callus induction using hybrids derived from three rice

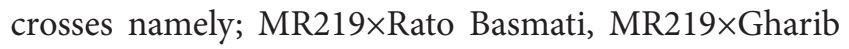
and MR219×Sadri. Callus production, on average, was

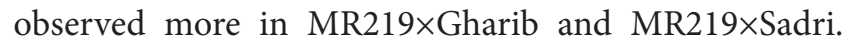
Growth regulators, 2,4-D and NAA, were equally added into each medium but only silver nitrate was observed as effective on callus induction. The result showed that medium $2 \mathrm{~A}(\mathrm{~N} 6+0.5 \mathrm{mg} / \mathrm{l} 2,4-\mathrm{D}+2 \mathrm{mg} / \mathrm{l} \mathrm{NAA}+10 \mathrm{mg} / \mathrm{l}$ $\mathrm{AgNO}_{3}$ ) had the highest frequency for callus production and silver nitrate doubled up the production of callus. Similar effect of silver nitrate was also reported by Lentini et al. ${ }^{39}$ and Laxmi and Reddy ${ }^{40}$ in indica rice. As an ethylene inhibitor, silver nitrate works by interfering with ethylene action, forming complexes, and inhibiting the effect of endogenously produced ethylene in the culture vessels ${ }^{7,35}$. The second highest production of callus was showed in medium 4 (N6 + MS + 0.5mg/L 2,4-D + 2mg/L NAA). The combination of medium N6 and MS without silver nitrate gave considerably good result. The same composition with silver nitrate in medium 3 (N6 + MS $+0.5 \mathrm{mg} / \mathrm{l} 2,4-\mathrm{D}+2 \mathrm{mg} / \mathrm{l} \mathrm{NAA}+10 \mathrm{mg} / 1 \mathrm{AgNO}_{3}$ ) showed lower result from both genotypes. Thus, the outcome of incorporating two basic medium N6 and MS with silver nitrate was not significant in callus induction. Without silver nitrate, N6 medium itself was found to have a better role in promoting callus development. Observed in medium 1A (N6 + 0.5mg/l 2,4-D + 2mg/l NAA), both genotypes gave a great number of callus. On the other hand, poor responses of calli were clearly observed in medium 1B (MS + 0.5mg/L 2,4-D + 2mg/L NAA) and $2 \mathrm{~B}\left(\mathrm{MS}+0.5 \mathrm{mg} / \mathrm{l} 2,4-\mathrm{D}+2 \mathrm{mg} / \mathrm{l} \mathrm{NAA}+10 \mathrm{mg} / \mathrm{AgNO}_{3}\right)$ in both genotypes. This finding showed that MS medium with or without modification was not effective for callus induction. Beside the importance of media optimization, cold pre-treatment is crucial in terms of anther culture. Sen et al. ${ }^{41}$ mentioned that excellent feedbacks of cold pre-treatment in embryogenic callus were because of some remarkable issues such as the deferment of pollen anther and the division of microspores that eventually develop a novel type of microspore or pollen grain. For indica cultivars, Alejar et al..$^{42}$ and Raj and Rangasamay ${ }^{43}$ recommended 5 to 8 days cold pre-treatment for better callus induction in both of MS and N6 media. Moreover, in the present studies, the best result was achieved with 7 days preservation time. This indicated that the duration of 7 days was essential to induce the formation of embryogenic microspores in the mentioned 3 crosses. Labbani et al. $^{44}$ also confirmed that duration of cold pre-treatment had a strong effect on the number of embryos produced, developed and formed. Duncan and Heberle ${ }^{45}$ claimed that, in cold pre-treatment, degradation process in anther tissues was reduced. Here it is also observed that in MS and N6 media, samples treated with 9, 10, 14 and 21 days released very low callus induction rates. This suggested that if the duration exceeded 5 to 8 days then the induction frequency of callus would have decreased. Without cold pre-treatment Sen et al ${ }^{41}$ did not observe any callus formation in several samples during anther culture. This report indicated that cold pre-treatment given to anthers was essential for callus induction. However, in the present study, fresh samples (without cold pre-treatment) were conducted for callus formation which surprisingly showed a little amount of callus. Significant interactions between cold pre-treatment and medium was also observed in this research. MR219×Gharib was more responsive for callus induction when 7 days of cold pre-treatment was given in N6 medium. This finding, therefore, suggested that interactions between cold pre-treatment and induction medium can greatly affect the growth of callus. From Figure 1, MRQ50/Gharib showed the highest percentage of callus formation. MRQ50/Rambir Basmati and MRQ50/E13 had similar value of callus induction frequency, $2.78 \%$. This was the lowest callus induction frequency in indica aromatic $\times$ indica aromatic rice crosses. Chen et al. ${ }^{15}$ reported that frequency of anther forming callus was tightly related to donor genotype. Hybrids derived from Gharib/MR219 performed highest value of callus induction frequency as shown in Figure 1. Therefore, hybrids of Gharib/MR219 were more efficient in producing callus. However, percentage of callus formation in MR219/E13 and MR219/ E11 were slightly similar to each other. From Figure 1, 6 genotypes of indica non-aromatic $\times$ indica aromatic rice crosses showed the significant value of callus induction frequency. MR219/Sadri, MR219/Gharib, and MR219/ Rato Basmati had significant different percentage of callus formation respectively. In anther culture technique, different rice genotypes had different callus formations. Therefore, anther culture ability of rice was influenced by different genotypes ${ }^{46}$. By comparing F1 hybrids from 12 different crosses, highest percentage of callus formation was found in MR219/Sadri cross, whereas MR219/ E7 gave the lowest callus induction frequency (Figure 1). MRQ50/Gharib had slightly similar percentage of callus formation. In addition, the callus induction frequency in MR219/E13 and MR219/E11 were approximately 
the same. Furthermore, MRQ50/Rambir Basmati and MRQ50/E13 had the same percentage of callus formation $(2.78 \%)$. From Figure 2, indica non-aromatic $\times$ indica aromatic rice crosses showed the highest value of callus induction frequency compared to indica $\times$ japonica and indica aromatic $\times$ indica aromatic rice crosses. The calli from these crosses have been successfully formed on N6 media supplemented with $0.5 \mathrm{mg} / \mathrm{l} 2,4$-Dichlorophenoxy acetic acid and $2 \mathrm{mg} / \mathrm{l}$ NAA (napthaleneacetic acid), preserved in 8 days. The success of anther culture technique cannot only be effected by rice genotypes, but also influenced by plant growth regulators that used in the culture media $^{30}$. According to Asaduzzaman et al. ${ }^{47}$, the ability of callus formation of rice varieties are largely dependent on culture medium. The MR219/Sadri performed the highest percentage (25.37\%) of callus formation, was the best genotype that produced more callus compared to other 11 genotypes and had ability and efficiency to form callus using anther culture technique. Naqvi et al. ${ }^{48}$ mentioned that the highest callus formation in genotype shows the best regeneration frequency. $F_{1}$ hybrids derived from 3 different indica aromatic $\times$ indica aromatic rice crosses, the MRQ50/Gharib had more ability to form callus. In indica $\times$ japonica rice crosses, the Gharib/MR219 could be used as the potential material for their crosses because it formed more callus compared to other genotypes. The genotypes in indica non-aromatic $\times$ indica aromatic rice crosses performed the significant value of callus induction frequency compared to another crosses. Furthermore, the indica non-aromatic $x$ indica aromatic rice crosses had higher percentage of callus formation and idenfied as potential to develop breeding materials through plant regeneration research. However, Sopory and Munshi ${ }^{49}$ stated that the selection of rice genotype should be based on their ability to produce green plants rather than based on ability to form more calli. Further confirmation of callus ability and efficiency in each genotype for different rice crosses need to be done by producing plantlets from plant regeneration study. In addition, comparisons between callus induction frequency in different genotypes and different rice crosses should be done using more types of different media for precision and accuracy.

\section{Conclusion}

These investigations demonstrated the performance of media and preservation time for callus induction in different types of rice crosses. Through optimizing the induction media and preservation time for cold pretreatment, a significant improvement of embryogenic potential of the callus was obtained. The composition of nutrients in medium $2 \mathrm{~A}$ made it the best medium among others as it was capable in inducing a great number of calli. The addition of silver nitrate into the N6 medium proved that it doubled up the production of embryogenic calli. Furthermore, this project verified the previous studies $^{17,18,24,25}$ in that N6 was superior to the MS medium. Analysis of variance indicated that there was a significant interaction between a medium and cold pre-treatment. Significant differences of the callus induction that were observed within indica/indica crosses suggested the importance of different factors for responsiveness of microspore callus formation in applying technique effectively in Indica type of rice. To sum up, it was concluded that efficiency establishment of callus formation in rice anther culture was greatly facilitated by the optimized induction medium and cold pre-treatment. In addition, the $\mathrm{F}_{1}$ hybrids from MR219/Sadri cross were identified as the most efficient for forming more calli. Furthermore, different crosses responded differentially in terms of callusing ability. Therefore, MR219/Sadri cross was selected as top performance $F_{1}$ hybrids because of its higher percentage of callus formation compared to others. This information might be helpful for integrated rice improvement especially in classical breeding and biotechnological approaches.

\section{Acknowledgement}

The authors wish to express their gratitude to the International Rice Research Institute (IRRI) and Malaysian Agricultural Research Development Institute (MARDI) for supplying rice genotypes and the Ministry of Higher Education Malaysia (MOHE) and the University of Malaya, Kuala Lumpur, Malaysia for UMRG grant No. RG 033/10 BIO during this research

\section{References}

1. Ernst, M., \& Fairhurst, T. H. (2002) Developments in rice production in Southeast Asia. Better Crops International, 15, Special Supplement.

2. Yoshida, S. (1981). Fundamentals of rice crop science. Philiphines: International Rice Research Institute.

3. Khush, G. S., \& Virk, P. S. Rice breeding: Achievements and future strategies. Crop Improv, 2000;27(2), 115-144. 
4. Abbasi, F. M., Akbar, K., Rehman, M. U., Khan, M. T., Iqbal, S., Fatima, A., Noshine, Ali, H., \& Abbasi, M. F. Cytological characterization of anther culture derived plants from the interspecific crosses between Oryza sativa $\times$ Oryzaaustralinesisand Oryza sativa $\times$ Oryzabrachyantha. African Journal of Biotechnology, 2011;10(17), 3269-3273.

5. Umba, D. U., Maluszynski, M., Szarejko, I., \& Zbieszezyk, J. (1991). High frequency of barley dihaploid-mutants from M1 after mutagenic treatment with $\mathrm{MNH}$ and sodium azide. Mutat Breed Newl, 1991;38, 8-9.

6. Zapata, F. J. (1992). IRRI Anther culture: procedure, progress, problem and prospects. In workshop on anther culture for rice breeders 12-24 October 1992. China National Rice Research Institute.

7. Sah, B. P. Response of genotypes to culture media for callus induction and regeneration of plants from rice anthers. Scientific World, 2008;6(6).

8. Guha, S., \& Maheshwari, S. C. (1964). In vitro production of embryos from anthers of Datura. Nature (London), 1964;204, 497.

9. Niizeki, H., \& Oono, K. Induction of haploid rice plant from anther culture. Proceedings of Japanese Academy, 1968;44, 554-557.

10. Brar, D. S., \& Kush, G. S. Cytogenetic manipulation and germplasm enhancement of rice (Oryza sativa L.). Genetic resources, chromosome engineering and crop improvement, 2006;2, 115-158.

11. Morinson, R. A., \& Evans, D. A. Haploid plant from tissue culture; new plant varieties in a shortened time frame. Biotechnology, 1988;6(6), 684-692.

12. Tran, T. T. X., \& Nguyen, T. L. Rice breeding for high grain quality through anther culture. Omonrice, 2011;18, 68-72.

13. Abe, T., \& Futsuhara, Y. Genotypic variability for callus formation and plant regeneration in rice (Oryza sativa L.). Theor. Appl. Genet, 1986;72, 3-10.

14. Gioi, T. D., \& Tuan, V. D. Anther Culture from Crosses between IR64 and New Plant Type Cultivar. Omonrice, 2004;12, 27-32.

15. Chen, C. C., Tsay. H. S., \& Huang C. R. (1986). Rice (Oryza sativa L.): Factors affecting androgenesis. In Y. P. S. Bajaj (Eds.), Biotechnology in agriculture and forestry. Berlin, Heidelberg: Springer-Verlag.

16. Maheshwari, S. C., Tyagi, A. K., Malhotra, K., Sopory, S. K. Induction of haploidy from pollen grains in Angiospermsthe current status. Theor appl Genet, 1980;58, 193-206.

17. Silva, T. D., \& Ratnayake, W. J. (2009). Anther culture potential of indica rice varieties, Kurulu Thuda and BG 250. Tropical Agricultural Research \& Extension, 2009;12(2).

18. Herath, H. M. I., Bandara, D. C., Samarajeewa, P. K. Effect of culture media for anther culture of indica rice varieties and hybrids of indica and japonica. Tropical Agricultural Research \& Extension, 2007;(10).
19. Li, M. F. (1992). Anther culture breeding of rice at the Chinese Academy of Agricultural Science. Anther culture for rice breeders. Hangzhou, China (pp. 75-86).

20. Ge, X. J., Chu, Z. H., Lin, Y. J., \& Wang, S. P. A tissue culture system for different germplasms of indica rice. Plant Cell Rep, 2006;25, 392-402.

21. Zaidi et al. Optimizing tissue culture media for efficient transformation of different indica rica genotype. Agronomy research, 2006;4(2), 563-575.

22. Roy, B., \& Mandal, A. B. Anther culture response in indica rice and variations in major agronomic characters among the androclones of a scented cultivar, Karnal local. African Journal of Biotechnology,2005; 4(3), 235-240.

23. Pathinayake, B. D., \& Johnson, D. L. Effect of culture media and temperature treatments on callus formation in anther culture of different rice (Oryza sativa L.) genotypes. Omonrice, 1989;10, 107-109.

24. Tran, D. G., \& Vuong, D. T. (2002). Effect of different media and genotypes on anther culture efficiency of F1 plants derived from crosses between IR64 and new plant type rice cultivars.

25. Ong, T. T., Vuong, D. T., \& Bui, B. B. Study on anther culture of $\mathrm{F} 1$ plants from crosses betweem aromatic and improved rice cultivars. Omonrice, 2001;9, 41-45.

26. Chu, C. C., Wang, C. S., Sun, C. S., Hsu, C., Yin, K. C., Chu, C. Y., \& Bi, F. Y. Establishment of an efficient medium for anther culture of rice through comparative experiments on the nitrogen sources. Science Sinica, 1975;18, 659-668.

27. Shen, J. H., Li, M. F., Chen, Y. Q., \& Zhang, Z. H. Breeding by anther culture in rice varieties improvement. Science. Agriculture Sin, 1982;2, 15-19.

28. Sarhadi, A. W., Ookawa, T., Yoshihashi, T., Madadi, A. K., Yosofzai, W., Oikawa, Y., \& Hirata, Y. Characterization of aroma and agronomic traits in Afghan native rice cultivars. Plant Production Science, 2009;12(1): 63- 69.

29. Buttery, R. G., Ling, L. C., \& Juliano, B. O. 2-Acetyl-1pyrroline: An important aroma component of cooked rice. Chem. Ind. (London), 1982;12, 958-959.

30. Chung, G. S. Tissue culture work on rice in Korea. In Rice tissue culture planning conference. International Rice Research Institute, Philippine, 1982;75-81.

31. Jain, R. K., Davey, M. R., Cocking, E. C., \& Wu, R. Carbohydrate and osmotic requirement for high frequency plant regeneration from protoplast-derived colonies of indica and japonica rice varieties. Journal of Experimental Botany, 1997;48(308), 751-758.

32. Shahsavari, E. Evaluation and optimizations of media on the tissue culture system of upland rice. International Journal of Agriculture \& Biology, 2010;12(4), 537-540.

33. Navarro-Alvarez, W., Baenziger, P. S., Eskridge, K. M., Shelton, D. R., Gustafson, V. D., \& Hugo, M. Effect of sugars 
in wheat anther culture media. Plant Breeding, 1994;112, 53-62.

34. Beyer, E. M. Silver ion: A potent anti-ethylene agent in cucumber and tomato. HortScience, 1976;11, 175-196.

35. Zhao, Y., Hull, A. K., Gupta, N. R., Goss, K. A., Alonso, J., Ecker, J. R., Normanly, J., Chory, J., \& Celenza, J. L. (Trp)dependent auxin biosynthesis in Arabidopsis: involvement of cytochrome P450s CYP79B2 and CYP79B3.Genes Dev, 2002;16, 3100-3112.

36. Murashige, T. P., \& Skoog, F. A revised medium for rapid growth and bioassays with tobacco tissue culture. Physiol. Plant, 1962;15(3), 473-497.

37. Chu, C. C., Wang, C. C., \& Sun C. S. (1978). The N6 medium and its application to anther culture of cereal crops. In Proc. Symp. Plant Tissue Culture, Science Press, Peking, pp. 45-50.

38. Chang, M. T., \& Coe, E. H. (2009). Doubled haploids. In A. L. Kriz, \& B. A. Larkins, (Eds.), Biotechnology in Agriculture and Forestry (pp.127-142). Molecular genetic approaches to maize improvement. Springer Verlag, Berlin, Heidelberg,

39. Lentini, Z., Reyes, P., Martinez, C. P., \& Roz, W. M. Androgenesis in highly recalcitrant rice genotypes with maltose and silver nitrate. Plant Sci, 1995; 110, 127-138.

40. Laxmi, G. V., \& Reddy, G. M. Anther culture of indica rice: Technical improvements in callus induction and green plant regeneration. J. Genet. Breed, 1997;51, 295-302.

41. Sen, C., Singh, R. P., Singh, M. K., \& Singh, H. B. Effect of cold pretreatment on anther culture of boro rice hybrids. The international Journal of Plant Reproductive Biology, 2011;3(1), 69-73.
42. Alejar, M. S., Zapata, F. J., Senadhira, D., Khush, G. S., \& Datta, K. (1995). Utilization of anther culture as a breeding tool in rice improvement. In M. Terzi, R. Cella, \& A. Falavigna (Eds.), Current Issues in Plant Molecular and Cellular Biology (pp. 137-142). Netherlands: Kluwer Academic Publishers.

43. Raj, S. K., \& Rangasamy, S. R. S. In vitro salt tolerance screening in long-term anther culture of rice (Oryza sativa L.) variety IR 50. J. Plant Physiol, 1993;124, 754-758.

44. Labbani, Z., Richard, N., de Buyser, J., \& Picard, E. Chlorophyllian durum wheat plants obtained by isolated microspores culture: importance of the pre-treatment. C. R. Biol, 2005; 328, 713-723.

45. Duncan, E. J., \& Heberle, E. Effect of temperature shock on nuclear phenomena in microspores of Nicotiana tabacum and consequently on plantlet production. Protoplasma, 1976;90, 173-177.

46. Evangelista, F. C., Aldemita, R. R., \& Ungson, L. B. Callusing and regeneration potential rice (Oryza sativa L.) genotypes towards the development for salt tolerance. Philippine Journal of Science, 2009;138(2), 169-176.

47. Asaduzzaman, M., Bari, M. A., Rahman, M. H., Khatun, N., Islam,M.A., \& Rahman,M.Invitroplantregenerationthrough anthercultureoffivericevarieties.JournalofBiologySciences, 2003;3(2), 167-171.

48. Naqvi, S. M .S., Sultana, R., \& Rasheed, H. Tissue culture studies in Oryza sativa L. Basmati 385 and Super Basmati. Pakistan Journal Botany, 2005;37, 823-828.

49. Sopory, S. K., \& Munshi, M. (1996). Anther Culture. In S. M. Jain, S. K. Sopory, \& R. E. Veilleus (Eds.). In vitro Haploid Production in Higher Plats (pp. 145-176). Netherland: Kluwer Academic Publishers. 